\title{
Rapid and High Yield Synthesis Method of Colloidal Nano Faujasite
}

Bo Wang, Yanzuo Li, Chenrui Shao, Mengyi Cui and Prabir K. Dutta*

\author{
Department of Chemistry and Biochemistry, \\ The Ohio State University, \\ 100 West 18th Avenue, Columbus, Ohio 43210
}

*Author to whom correspondence should be addressed (dutta.1@osu.edu) 


\begin{abstract}
Conventional synthesis methods of isolated, colloidal nano faujasites (nanoFAU) have been limited by low yield (typically $<10 \%$ ) and long synthesis time (days). In this study, synthesis of colloidal nanoFAU by microwave heating and a recently reported dehydration/rehydration hydrothermal (DRHT) process is examined. All studies are done with a literature reported 3-day aged composition (Comp A, $0.048 \mathrm{Na}_{2} \mathrm{O}: 2.40$ (TMA) $2 \mathrm{O}(2 \mathrm{OH}): 1.2$ (TMA) $)_{2} \mathrm{O}(2 \mathrm{Br}): 4.35 \mathrm{SiO}_{2}: 1.0 \mathrm{Al}_{2} \mathrm{O}_{3}: 249 \mathrm{H}_{2} \mathrm{O}, \mathrm{TMA}^{+}$is tetramethylammonium). Using this composition in a hydrothermal process, nanoFAU with 5\% yield is obtained in 96 hours. With microwave heating for 4 hours, micron- sized zeolite A crystals and nanoFAU are formed with yields of $13 \%$ and $7 \%$, respectively. With DRHT, nanoFAU of Si/Al ratio 2.23 is formed in 20 hours with yield of 7\%. It has been reported that supernatant of composition A after the hydrothermal process can be cycled with mid-synthesis addition of $\mathrm{NaOH}$, resulting in yield of nanoFAU of $43 \%$ in 10 cycles in 576 hours. A synthesis protocol involving 29 hours of continuous DRHT process with mid-synthesis addition of $\mathrm{NaOH}$ over 6 cycles produced nanoFAU with a yield of $93 \%$, average particle size of $29 \pm 7 \mathrm{~nm}$, as measured by TEM, a Si/Al ratio of 1.76 , and surface area of $625 \mathrm{~m}^{2} / \mathrm{g}$. Practical implications, like cost and $\mathrm{TMA}^{+}$removal for the reported synthesis method is also included.
\end{abstract}

\title{
Keywords
}

Colloidal nano faujasite; Rapid Synthesis; Dehydration/Rehydration Hydrothermal; Microwave; Supernatant 


\section{Introduction}

Zeolites are microporous crystalline aluminosilicates with enclosed cages and channels of molecular dimensions [1]. With narrow pore size distribution and strong catalytic active sites, zeolites find applications in energy and environment related fields [2-4]. The sizes of zeolite crystals can vary from microns to nanometers. Nanometer sized zeolites $(<100 \mathrm{~nm})$ are used in synthesis of zeolite membranes [5], sensing [6], catalysis [7], photocatalysis [8] and biomedical diagnostics [9].

Synthesis conditions for similar zeolite frameworks of different sizes are carried out by different routes [10]. Micron sized zeolites are produced in tonnage quantities from heterogeneous gel systems, with high yield (>80\%) and wide particle size distribution [1]. Comparatively, synthesis of isolated nanozeolite particles with narrow size distribution requires a clear-solution synthesis system [10,11], with low yield and long synthesis times. Though there are numerous research papers and patents on nanozeolites, there are no commercial sources of nanozeolites.

We have recently reported on the use of nanocrystals of faujasite (nanoFAU) for fabrication of membranes aimed towards $\mathrm{CO}_{2} / \mathrm{N}_{2}$ separation [12-18]. In one of these strategies, a $200 \mathrm{~nm}$ layer of nanoFAU is deposited on a porous polyethersulfone support by vacuum deposition. On top of the nanoFAU layer, a $100 \mathrm{~nm}$ thin amine polymer layer (which acts as the active medium for $\left.\mathrm{CO}_{2} / \mathrm{N}_{2}\right)$ is formed $[15,16,18]$. With the nanoFAU layer present, the transport properties are significantly improved [16]. It is proposed that the nanoFAU layer provides a smoother surface, which makes it feasible to deposit thinner polymer layers. The zeolite layer also ensures minimum penetration of the polymer into the porous support $[15,16]$. Besides the 
improved transport properties of the nanoFAU-polymer composite, the manufacturability of the membrane on a large scale via roll-to-roll machines is possible [19]. In a second strategy, we have used nanoFAU as seeds for secondary growth within and on top of porous polymer supports, with excellent $\mathrm{CO}_{2} / \mathrm{N}_{2}$ transport properties [13,14,17].

A major limitation to manufacturing such zeolite polymer composite membranes is the lack of availability of nanoFAU. As an example, $\mathrm{CO}_{2}$ capture from a $600 \mathrm{MW}$ power plant would require 1 million $\mathrm{m}^{2}$ surface area of membrane, which will require about $\sim 1,000 \mathrm{~kg}$ nanoFAU. Since there are no commercial vendors of nanoFAU, and the current high yield published (and patented) process takes more than 3 weeks [20], we have investigated methods to accelerate the nanoFAU synthesis process. There are many reports of growth of nanoFAU, but requirements are that the nanoparticles be isolated, which restricts us to "clear solution" synthesis.

Several key factors control the synthesis process of nanoFAU [10,11,20-24]. First, tetramethylammonium cations (TMA) are necessary to stabilize sodalite cages, which are critical structural units of FAU $[11,25]$. Particle size of nanoFAU can be controlled by adjusting the ratio of tetramethylammonium bromide (TMABr) and $\mathrm{TMAOH}[24]$. Second, $\mathrm{Na}^{+}$concentration in the synthesis composition has to be controlled $(\mathrm{Na} / \mathrm{Al}<0.07)$ in order to avoid formation of zeolite A. Low $\mathrm{Na}^{+}$concentration, on the other hand, is the primary reason for low yield in FAU synthesis [11,20,23]. Mid synthesis $\mathrm{Na}^{+}$addition is reported to increase yield of nanoFAU [23]. Another method to increase yield of nanoFAU is by recycling the supernatant left behind after crystallization, and a procedure with 10 cycles of reusing the supernatant resulted in $43 \%$ cumulative yield of nanoFAU in 576 hours [20]. Recently, a template free synthesis method of 
nanoFAU has been reported, with high alkalinity in clear solution synthesis composition [26]. Strict control of parameters like mixing temperature and gel particle dissolution are required.

Seeding [27,28], microwave (MW) [29] and dehydration/rehydration hydrothermal (DRHT) synthesis strategies[12-14] are reported to improve synthesis rate of micron sized zeolites. This study is focused on increasing synthesis rate and yield of colloidal nanoFAU zeolite with a well-studied clear solution synthesis composition [24]. Seeding, MW and DRHT are compared and optimized to accelerate nanoFAU synthesis. X-ray Diffraction (XRD) is employed to study the crystalline phase of zeolite samples. Dynamic Light Scattering (DLS) is used to measure particle size of colloidal zeolites. Transmission Electron Microscopy (TEM) is used for zeolite crystal morphology characterization. ${ }^{29} \mathrm{Si}$ Nuclear Magnetic Resonance $\left({ }^{29} \mathrm{Si}\right.$ NMR) provides information on $\mathrm{Si} / \mathrm{Al}$ of samples. $\mathrm{N}_{2}$ adsorption analyzed by the BrunauerEmmett-Teller (BET) method was used to calculate the surface area and pore size distribution of nanoFAU samples.

\section{Experiments}

\subsection{Chemicals}

Ludox HS-30 colloidal silica $\left(\mathrm{SiO}_{2}, 30 \%\right)$, aluminum isopropoxide $\left(\mathrm{Al}\left(\mathrm{O}-\mathrm{CH}\left(\mathrm{CH}_{3}\right)_{2}\right)_{3}\right.$, 98\%) and tetramethylammonium bromide $\left(\left(\mathrm{CH}_{3}\right)_{4} \mathrm{NBr}, 98 \%\right)$ were purchased from Aldrich (Milwaukee, WI, USA). Tetramethylammonium hydroxide $\left(\left(\mathrm{CH}_{3}\right)_{4} \mathrm{NOH}, 25 \%\right.$ aqueous) was purchased from SACHEM Inc. Sodium hydroxide (NaOH, 99\%) pellet from Fisher Scientific $(\mathrm{NaOH}, 99.0 \%)$ was used. All chemicals were used without purification. Pure water was produced by a Millipore ultrapure water system. 


\subsection{Synthesis Procedure}

Zeolite Synthesis NanoFAU synthesis using the composition $0.048 \mathrm{Na}_{2} \mathrm{O}: 2.40$

(TMA) $)_{2} \mathrm{O}(2 \mathrm{OH}): 1.2(\mathrm{TMA})_{2} \mathrm{O}(2 \mathrm{Br}): 4.35 \mathrm{SiO}_{2}: 1.0 \mathrm{Al}_{2} \mathrm{O}_{3}: 249 \mathrm{H}_{2} \mathrm{O}\left(\mathrm{TMA}^{+}\right.$is

tetramethylammonium) was prepared as reported in literature [24]. Briefly, 26.2 g Ludox HS-30 as silicon source and $10.46 \mathrm{~g} \mathrm{TMAOH}$ were mixed and stirred at room temperature for $30 \mathrm{~min}$ before use. For alumina source, $76.5 \mathrm{~g} \mathrm{H}_{2} \mathrm{O}$ and $52.3 \mathrm{~g}$ TMAOH was mixed, and $12.5 \mathrm{~g}$ aluminum isopropoxide was dissolved in this mixture at $70^{\circ} \mathrm{C}$ in a water bath. After cooling to room temperature, $11.3 \mathrm{~g} \mathrm{TMABr}$ was added to the mixture and stirred at room temperature for 15 min. Finally, the silicon and aluminum source were combined slowly and aged at room temperature with stirring for 3 days to obtain aged solution (AgComp A). NanoFAU was prepared from AgCompA by hydrothermal, microwave and DRHT methods.

Supernatant Isolation After completion of nanoFAU synthesis, the supernatant recovered after centrifugation of nanoFAU particles was used in various experiments as detailed below. This supernatant was stored in refrigerator at $2{ }^{\circ} \mathrm{C}$ before use.

Seed Assisted Solution $100 \mathrm{mg}$ of nanoFAU seeds were added to the CompA solution $(180 \mathrm{ml})$ before 3-day room temperature aging, and used for zeolite synthesis.

Microwave (MW) Heating $25 \mathrm{~g}$ of AgCompA was placed in MW tubes and heated by microwave at $300 \mathrm{~W}$ for definite times with magnetic stirring. Microwave treatment was accompanied by air cooling with equilibrium temperature of $135-140^{\circ} \mathrm{C} . \mathrm{CEM}$ Discover-SP microwave reactor was used in this study.

Dehydration/Rehydration Hydrothermal (DRHT) Synthesis In DRHT synthesis, $100 \mathrm{~g}$ of AgCompA was placed in the flask of reactor. Dehydration of precursor was realized by water evaporation from the precursor during reflux. The evaporated water was condensed in a 
condenser and collected in the constant pressure funnel. Rehydration was done by adding water back to the reaction medium with constant rate, while under reflux. Certain amount of $\mathrm{NaOH}$ was dissolved in collected water as specified in the text, and added back to the reaction mixture in some cases. Dehydration and rehydration takes 30 min.

Yield of nanoFAU was calculated as follows. Total mass of raw material was calculated as the mass of $\mathrm{SiO}_{2}$ and $\mathrm{Al}_{2} \mathrm{O}_{3}$ in the initial clear solution. Mass of product was the weight of nanoFAU particles isolated from the product mixture with $30 \%$ of water weight subtracted (based on the weight loss during thermal analysis) [24]. The yield of nanoFAU was calculated as weight of product divided by the weight of raw materials (an example is provided in the Supplementary Section).

\subsection{Characterization}

A Bruker D8 X-Ray Diffractometer using $\operatorname{CuK}_{\alpha}(\lambda=1.5405 \AA)$ radiation were used to characterize the crystallinity of zeolite. Particle size and zeta potential of nanoFAU were characterized with Malvern Zetasizer. Sorvall ${ }^{\mathrm{TM}} \mathrm{MX}$ ultracentrifuge and Beckman Coulter Allegra 64R benchtop centrifuge were used for particle separation. FEI Tecnai F20 S/TEM was employed to collect TEM images of nanoFAU samples. ImageJ was used to measure sizes in TEM images for particle size distribution. A Bruker DSX $300 \mathrm{MHz}$ superconducting magnet equipped with a dual channel (H-X) MAS probe was used to collect high-resolution ${ }^{29} \mathrm{Si}$ (59.6 MHz) spectra. Nova 2200e BET Surface Area Analyzer from Quantachrome was employed to collect the $\mathrm{N}_{2}$ adsorption isotherm of zeolite samples (samples heated to $600^{\circ} \mathrm{C}$ for 12 hours), with surface area and pore size distribution calculated with Brunauer-Emmett-Teller (BET) and 
Barrett-Joyner-Halenda (BJH) theories. Carbon and nitrogen analysis was done by Galbraith Laboratories, TN.

\section{Results}

The composition of interest in this study is $0.048 \mathrm{Na}_{2} \mathrm{O}: 2.40$ (TMA) $)_{2} \mathrm{O}(2 \mathrm{OH}): 1.2$ (TMA) $)_{2} \mathrm{O}(2 \mathrm{Br}): 4.35 \mathrm{SiO}_{2}: 1.0 \mathrm{Al}_{2} \mathrm{O}_{3}: 249 \mathrm{H}_{2} \mathrm{O}$ (Comp A) [24]. Several experiments were carried out with this composition after 3 days of aging (the aged material is henceforth referred to as AgComp A).

\subsection{Experiments with AgCompA}

Particles in AgComp A were isolated by high speed centrifuge (150,000 rpm) for 2 hours, and TEM images and XRD patterns were collected. The isolated particles have diameter of around $15 \mathrm{~nm}$ (Figure 1S) and are amorphous by XRD (Figure 1S), as has been noted previously [22]. Hydrothermal treatment at $100^{\circ} \mathrm{C}$ of AgComp A for $96 \mathrm{~h}$ produced nanoFAU of size $\sim 40$ $\mathrm{nm}$ (as measured by dynamic light scattering, DLS) with 5\% yield; the yield in the literature is reported as $12.5 \%[24]$.

Seeding Seeding has been reported to accelerate zeolite growth [27,28]. NanoFAU crystals ( $40 \mathrm{~nm}$ ) were introduced into AgComp A (loading of $100 \mathrm{mg}$ of FAU per $180 \mathrm{ml}$ ) before aging and hydrothermal synthesis at $100^{\circ} \mathrm{C}$. Figure $2 \mathrm{~S}$ shows the XRD of the recovered product at time intervals of $24 \mathrm{~h}$. It took $96 \mathrm{~h}$ for the crystallization to be complete, a time scale comparable to hydrothermal synthesis with AgComp A without seeding, and with 6\% yield (DLS particle size $56 \mathrm{~nm})$.

Microwave treatment Microwave radiation has been reported to accelerate the kinetics of zeolite crystallization [29-32]. Upon treating AgComp A at $300 \mathrm{~W}$ of microwave radiation, the solution turned turbid in 4 hours. Figure 1a shows the SEM image of the product, and consists of 
large cubic as well as smaller particles. The large particles were captured by low speed centrifugation (2500 rpm for 2 hours) and were primarily zeolite A with small amount of FAU (XRD shown in Figure 1bi). Smaller particles were separated by high speed centrifugation (22,000 rpm for 1 hour) and was pure FAU (Figure 1bii), with average particle size of $96 \mathrm{~nm}$ (DLS) and a yield of $7.3 \%$.

Dehydration-Rehydration Hydrothermal (DRHT) treatment The DRHT procedure involves removal of a certain amount of water from the reaction mixture during the hydrothermal process by distillation. The concentrated reaction mixture is heated for a period of time, and then the reaction system is rehydrated with the same amount of water (can be pure water or mixed with specific solutes), with the entire process occurring under reflux conditions [12].

$25 \mathrm{ml}$ ( $25 \%$ of the water) was removed from $100 \mathrm{ml} \mathrm{AgComp} \mathrm{A} \mathrm{by} \mathrm{distillation}$ over $30 \mathrm{~min}$, followed by reflux for 19 hours, and then re-addition of water over $30 \mathrm{~min}$, all under reflux conditions using the reactor shown in Figure 3S. This process resulted in $\sim 64 \mathrm{~nm}$ nanoFAU (DLS) with 7\% yield, and the XRD is shown in Figure 2a. Figure 2b shows the TEM of these colloidal crystals, with Figure 2c showing the particle size distribution based on the TEM. The size distribution from the TEM peaked at $21 \mathrm{~nm}$ with a standard deviation of $4 \mathrm{~nm}$. ${ }^{29} \mathrm{Si}$ SSNMR of this sample is shown in Figure 2d, and calculates to a Si/Al ratio of 2.23. Crystallinity, particle size distribution and Si/Al ratio of nanoFAU with DRHT (total time 20 hours) are comparable with the product from the 96 hours by hydrothermal synthesis method [24]. Reflux time was optimal with 19 hours; lower times resulted in incomplete crystallization of FAU (data not shown). The amount of water removed during the dehydration step was critical; at $25 \%$ water removal pure nanoFAU is formed (Figure 2), but with $50 \%$ water removal, the system is directed towards LTA (XRD data shown in Figure 4S). This is reasonable since 
removal of $25 \%$ water approaches approximately the upper limit of $\mathrm{Na}^{+}$concentration necessary for pure FAU synthesis (Na/Al of 0.07) [11].

Table 1 compares the sizes and yields obtained by the various processes. The microwave is the fastest process for producing nanoFAU, but the considerable yield of LTA makes this process ineffective obtaining for high yields of nanoFAU.

\subsection{Studies with supernatant of AgComp A after initial crystallization}

Earlier reports in the literature recognized that hydrothermal synthesis with AgComp A for $96 \mathrm{~h}$ resulted in low yields of nanoFAU, leaving behind significant amounts of reactants in the supernatant [20]. Strategies for generating zeolite from this supernatant solution include midsynthesis addition of $\mathrm{Na}^{+}$to the supernatant, followed by hydrothermal treatment. Ten such cycles spread out over 576 hours resulted in nanoFAU yield of $43 \%$, with a $0.1 \%$ per hour synthesis rate [20].

The supernatant recovered after $96 \mathrm{~h}$ of hydrothermal treatment of AgComp A was used for several experiments (abbreviated as SupHTAgCompA, results summarized in Table 1). SupHTAgCompA was extensively centrifuged (150,000 rpm for 2 hours) and a solid was recovered. XRD pattern of the recovered solid shows both nanoFAU and amorphous particles (Figure 3c). TEM indicates the presence of $\sim 15 \mathrm{~nm}$ FAU as shown in Figure 3ab. DLS data shown in Figure 3d indicates particle sizes of 7 and $21 \mathrm{~nm}$. Thus, SupHTAgCompA appears to contain both amorphous material and nanoFAU crystals.

Microwave treatment SupHTAgCompA (20 ml) was treated with $\mathrm{NaOH}(12 \mathrm{mg})$, and then subjected to microwave radiation of $300 \mathrm{MW}$. Solution turned turbid within an hour, and XRD of the product showed only FAU (Figure 5S). Low speed centrifugation (2500 rpm for 2 
hours) was used to remove the large visible particles, and higher speed ultracentrifugation (22,000 rpm for 1 hour) resulted in recovery of nanoFAU with a size of $\sim 32 \mathrm{~nm}$ (DLS), and yield of $10 \%$. In another set of experiments, three cycles of microwave radiation, each for one hour with $\mathrm{NaOH}$ (12 $\mathrm{mg}$ for each cycle) added prior to each microwave heating cycle was carried out (there was no centrifugation between the cycles). There were both large micron sized FAU (yield 26\%) and nanoFAU (45 nm (DLS), yield 35\%) in the product after 3 cycles. Figure 5S shows the XRD of the small and large crystals, respectively. Focusing only on the nanoFAU, the yield rate was $11 \%$ per hour for the 3 cycles.

DRHT treatment Several DRHT experiments were carried out with SupHTAgCompA $(100 \mathrm{ml})$. The first protocol was $30 \mathrm{~min}$ of dehydration $+30 \mathrm{~min}$ of reflux $+30 \mathrm{~min}$ of rehydration for a total of $90 \mathrm{~min}$ for the first cycle. During the rehydration step instead of adding back the collected water $(40 \mathrm{~mL})$, a solution of $\mathrm{NaOH}$ was added back (60 $\mathrm{mg} \mathrm{NaOH}$ dissolved in $40 \mathrm{~mL}$ of the collected water for each cycle). The cycles were repeated 6 times until FAU no longer formed. Figure 4a shows the XRD diffraction curves of the product recovered for the 6 cycles. Pure FAU was synthesized during all 6 cycles. Large particles of other phases, including zeolite A, starts to form in $7^{\text {th }}$ cycle (data not shown). Figure $4 \mathrm{~b}$ shows the size (DLS)/yield curve. Cumulative yield increased evenly at each cycle, with $12 \%$ yield at each cycle on average. The particle size of nanoFAU increased from $30 \mathrm{~nm}$ to $60 \mathrm{~nm}$ (DLS) in 6 cycles.

The nanoparticles collected after the $2^{\text {nd }}$ (DRHT-2), $4^{\text {th }}$ (DRHT-4) and $6^{\text {th }}$ (DRHT-6) cycles in the DRHT process were further characterized. Surface areas of DRHT-2, DRHT-4 and DRHT-6 were $504 \mathrm{~m}^{2} / \mathrm{g}, 685 \mathrm{~m}^{2} / \mathrm{g}$ and $666 \mathrm{~m}^{2} / \mathrm{g}$, respectively. Morphologies of nanoFAU particles of DRHT-2, DRHT-4 and DRHT-6 were characterized by TEM at various magnifications. As shown in Figure 5a, atomic fringes confirm crystallization of nanoFAU 
particles. Based on Figure 5b, which is a collection of large number of particles, a size distribution was obtained (measurement of 100 particles). Particles recovered after DRHT-2, DRHT-4 and DRHT-6 have average sizes of $23 \pm 4 \mathrm{~nm}, 25 \pm 4 \mathrm{~nm}$ and $31 \pm 4 \mathrm{~nm}$, respectively. DLS indicates the particle size increases from $30 \mathrm{~nm}$ to $60 \mathrm{~nm}$; the reason of larger particle size measured with DLS is possibly due to the formation of weak aggregates [33]. Si/Al ratio of nanoFAU particles in DRHT-2, DRHT-4 and DRHT-6 as measured by ${ }^{29} \mathrm{Si}$ SSNMR are shown in Figure 6, with $\mathrm{Si} / \mathrm{Al}$ ratios of 1.70, 1.50 and 1.51, respectively.

A second DRHT protocol with SupHTAgCompA $(100 \mathrm{ml})$ involved 2 hours per cycle (30 min of dehydration +1 hour of reflux +30 min of rehydration), with rehydration with a $\mathrm{NaOH}$ solution (60 mg per cycle). Only the first two cycles produced nanoFAU, with a total yield of $62 \%$ and a particle size of $54 \mathrm{~nm}$ (DLS) after the second cycle. Figure $6 \mathrm{~S}$ shows the XRD of the products obtained with this DRHT protocol.

With SupHTAgCompA, DRHT increases rate of nanoFAU formation to $8 \%$ per hour for the first DRHT protocol (30 min of dehydration $+30 \mathrm{~min}$ of reflux $+30 \mathrm{~min}$ of rehydration) and $16 \%$ per hour for the second DRHT (30 min of dehydration +1 hour of reflux +30 min of rehydration) protocol.

Control Experiments Several control experiments were carried out to evaluate the nature of AgCompA and the supernatants.

Twenty five percent less water was used to prepare Comp A, aged for 3 days and then subjected to DRHT treatment. Figure 7S shows the XRD of the recovered product after a 20 hour protocol (30 min of dehydration +19 hours of reflex +30 min of rehydration). Only sodalite crystals together with amorphous particles were recovered. This indicates that removing the water initially does not have the same effect as the dehydration step in the DRHT protocol. 
In a second control experiment, the effect of rehydration was evaluated by subjecting AgComp A to a $19 \frac{1}{2}$ hours protocol (30 min water removal $+19 \frac{1}{2}$ hours of reflux, no water added back). The XRD of the recovered product is shown in Figure 8S, and indicates the formation of FAU. However, when the supernatant from this composition $(100 \mathrm{ml})$ was subjected to 6 cycles of DRHT ( 30 min of dehydration +1 hour of reflux +30 min rehydration with aq $\mathrm{NaOH}(60 \mathrm{mg})$ ), the first two cycles result in FAU + SOD (Figure 9S), whereas the latter cycles were pure FAU. It appears that the rehydration step in DRHT is necessary to form FAU during all cycles.

For a third control experiment, AgCompA was treated under hydrothermal conditions at $100^{\circ} \mathrm{C}$, and the supernatant was recovered after 2 and 3 days (instead of the 4 day treatment above). Both these solutions (100 $\mathrm{ml}$ each) were subjected to DRHT (30 min water removal +30 min reflux +30 min rehydration with aq $\mathrm{NaOH}(60 \mathrm{mg})$. Figure 10S shows the XRD patterns of particles after the $2^{\text {nd }}$ and $4^{\text {th }}$ cycles with 2 days supernatant. LTA was the majority phase for the 2 day sample, and for the 3 days sample, FAU was the majority phase, but LTA was still present. Thus, it is essential to go through the 4-day hydrothermal treatment to create the supernatant with the appropriate structures necessary to form faujasite.

\subsection{Optimized synthesis of nanoFAU with AgComp A using DRHT process}

The DRHT process was used for both AgCompA and the supernatant obtained after the initial zeolite growth. This was done in two ways. First, AgComp A $(100 \mathrm{ml})$ was heated with DRHT as described in section 3.1 (30 min of dehydration (removal of $25 \%$ water) +19 hours of reflux +30 min of dehydration). The nano FAU and the supernatant was separated by centrifugation. The supernatant was then subjected to 6 cycles of DRHT (30 min dehydration 
(removal of $40 \%$ of water) +30 min reflux +30 min rehydration with aq. $\mathrm{NaOH}(60 \mathrm{mg})$ ). Products were recovered by centrifugation at each stage. Figure 7a shows the XRD of the product at each cycle and Figure 7b shows the yields and crystal size (DLS) change for each cycle. Total yield of $75 \%$ of pure nanoFAU was obtained over the 29 hour process, but with seven total centrifugation steps (these centrifugations have to be carried out with an ultracentrifuge because of the small size of crystals).

This entire process was then repeated with only one centrifugation step after the final cycle. The process starting with AgCompA (100 ml) was 1 hour of dehydration (removal of $25 \%$ water) +19 hours of reflux +1 hour of rehydration plus 6 cycles of 30 min dehydration (removal of $40 \%$ water $)+30 \mathrm{~min}$ reflux +30 min rehydration with aq $\mathrm{NaOH}(60 \mathrm{mg} / \mathrm{cycle})$ added during each rehydration process, without any intermediate centrifugation steps. This process took 29 hours to complete, and the final centrifugation led to a yield of $93 \%$, with particle size of $89 \mathrm{~nm}$ (DLS) and XRD typical of FAU (Figure 8a). The particle size from the TEM is $29 \pm 7 \mathrm{~nm}$ (Figure 8b, c). $\mathrm{Si} / \mathrm{Al}$ ratio of the particle is 1.76 , as calculated from ${ }^{29} \mathrm{Si}$ SSNMR (Figure $8 \mathrm{~d}$ ). The nanoFAU particles has BET surface area of $625 \mathrm{~m}^{2} / \mathrm{g}$ and external surface area of $219 \mathrm{~m}^{2} / \mathrm{g}$ (Figure 9). All of the yields and sizes of the zeolite products are summarized in Table 1.

\section{Discussion}

In previous studies of nanoFAU synthesis from clear solutions, the following aspects were recognized $[10,11,20-25]$ :

- $<10 \%$ yields of nanoFAU are typically obtained;

- Typical synthesis takes days;

- The supernatant solution after removing the initial crop of zeolite is saturated with nutrients 
- Addition of $\mathrm{Na}^{+}$will promote growth of nanoFAU, and this process can be repeated;

- The $\mathrm{Na}^{+}$concentration is critical for phase purity, with LTA and FAU being competing phases.

In this study, we chose a particular composition which has been optimized previously [24], and examine ways to improve the yield and equally importantly the rate of crystallization.

\subsection{Influencing the synthesis of Composition A.}

With conventional hydrothermal treatment of AgComp A, nanoFAU is formed in 96 hours with overall yield of $\sim 5 \%$. Seeding of AgComp A does not appear to have any effect on the crystallization. Seeding is usually more effective for gel-based systems, since seeds promote growth of crystals larger than the initial seeds [34]. Both microwave radiation and DRHT also produced nanoFAU at yields of 7 and $6.9 \%$, respectively, similar to the regular hydrothermal process. Microwave heating did this in 4 hours, and DRHT in 20 hours. Microwave also resulted in rapid growth of large zeolite A crystals, with yield of $39 \%$, indicating that microwave is primarily directing the synthesis towards LTA (Figure 1).

Based on the comparisons of the methods (Table 1), the optimal process to obtain the largest amount (yield $\sim 7-8 \%$ ) of nanoFAU ( $\mathrm{Si} / \mathrm{Al} 2,23)$ from AgComp $\mathrm{A}$ in the shortest period of time ( 20 hours) is via the DRHT method. With DRHT protocol, nanoFAU synthesis rate has increased from $0.1 \%$ per hour in a conventional hydrothermal process [21] to $\sim 0.4 \%$ per hour. Microwave can produce similar nanoFAU yields in 4 hours, but this process also depletes the nutrients from the composition because of LTA formation, and the supernatant cannot be used for subsequent experiments. 


\subsection{Efficient synthesis of nanoFAU from Supernatant of Comp A:}

The supernatant recovered after the hydrothermal process (4 days hydrothermal or 20 hours DRHT) with AgComp A contains small crystals of FAU, along with amorphous particles, as shown in Figure 3. This supernatant is unique in the sense that it is primed for growth into FAU either by microwave or DRHT. The microwave treatment of the supernatant results in only FAU, both large (microns) and nanoFAU, suggesting that FAU is favored to be nucleated in the supernatant (Figure 5S). The larger FAU crystals arise since the microwave provides the added energy needed to overcome the higher activation energy of crystal growth [29]. Higher temperatures are reported to increase nanoFAU crystallite size [23]. Microwave is known to produce a narrower particle size distribution [29], but we observe two very different particle size distributions. This is because there are two types of FAU nuclei in the supernatant, the structures that are already zeolitic, and the "amorphous"-like materials that are evident in the TEM (Figure 3). It is the former that grow into the larger crystals, whereas the latter produce the nanocrystals. Thus, the embryonic structures present in the 4-day hydrothermal or 20 hour DRHT supernatant favor FAU even with aggressive microwave treatment.

It is well recognized in the literature that the amount of $\mathrm{Na}^{+}$added in mid-synthesis is critical $[23,35]$. In small amounts, $\mathrm{Na}^{+}$has been proposed to facilitate growth of FAU from the nuclei that are present, but without new nucleation [11]. We propose that during each cycle, the added $\mathrm{Na}^{+}$is helping growth of current FAU nuclei (including the small $<15 \mathrm{~nm}$ FAU crystals identified in the TEM, Figure 3), as well as the extra hydroxide helping nucleation of new FAU nuclei from the embryonic particles, which grow into crystals with more $\mathrm{Na}^{+}$(added during the next cycle). The role of $\mathrm{Na}^{+}$in breaking and reorganizing the gel structure has been noted [36]. If 
too much $\mathrm{Na}^{+}$is added at once, then LTA is nucleated in the supernatant, and LTA formation is rapid and utilizes all available nutrients.

With each cycle of DRHT on the supernatant, the properties of the recovered nanoFAU are slightly different in size and more importantly, in $\mathrm{Si} / \mathrm{Al}$ ratio. The $2^{\text {nd }}, 4^{\text {th }}$ and $6^{\text {th }}$ cycle of the DRHT process lead to nanoFAU particles of size $23 \pm 4 \mathrm{~nm}, 25 \pm 4 \mathrm{~nm}$ and $31 \pm 4 \mathrm{~nm}$, and Si/Al ratio of 1.70, 1.50 and 1.51, respectively (Figure 5,6). A size increase with midsynthesis addition of $\mathrm{NaOH}$ for hydrothermal synthesis of nanoFAU has been reported [23]. Decrease of the $\mathrm{Si} / \mathrm{Al}$ ratio in successive cycles from the initial 2.29 to 1.5 is consistent with increased alkalinity [35]. In this regard, a DRHT experimental protocol using $\mathrm{NaCl}$ instead of $\mathrm{NaOH}$ would be of interest [21]. This experiment would also establish the role of $\mathrm{OH}^{-}$versus $\mathrm{Na}^{+}$in facilitating nucleation versus crystal growth [37].

\subsection{Role of DRHT process}

The DRHT process with both the AgComp A and the supernatant after the first heating cycle is very effective in producing nanoFAU. The dehydration results in a more alkaline solution which speeds crystal growth by restructuring and rearranging the embryonic particles. Also, the dehydration increase the $\mathrm{Na}^{+}$content, favoring growth of FAU from the nuclei that already exists. However, there is more to the dehydration step than just increasing the basicity. A starting composition with $25 \%$ less water from the beginning using AgComp A led to SOD

formation (Figure 7S). Rehydration is also essential to get the balance $\mathrm{Na}^{+} / \mathrm{Al} / \mathrm{OH}^{-}$appropriate to FAU growth for the next cycle, since lack of it led to mixtures of SOD and FAU (Figure 9S).

\subsection{Comparison with literature}


We compare and discuss the compositions reported in the literature that have used TMA for nanoFAU synthesis, and are shown in Table 2. There is a report of nanoFAU synthesis with high yields using only a sodium aluminosilicate system (also included in Table 2) [26]. There has been a steady evolution in synthesis of nanoFAU since the first report of clear solution synthesis. Schoeman et al. reported nanoFAU synthesis from clear solution composition with $\mathrm{TMA}^{+}$as directing agent [11], with diameter around $100 \mathrm{~nm}$, but the yield was not specified, and the synthesis time took 100 hours to complete. Zhu et al. successfully synthesized nanoFAU with different $\mathrm{Si} / \mathrm{Al}$, with time periods of $336 \mathrm{~h}$, but with unspecified yields [21]. Mintova et al. reported the synthesis of nanoFAU with smaller particle size $(50 \mathrm{~nm})$, over a period of $100 \mathrm{~h}$, but the yield was not specified [22]. A 2-stage varying temperature synthesis method of nanoFAU has been reported by Li et al. [23]. In this method, nucleation of zeolite was hindered by rapid increase of temperature at different nucleation times. With longer nucleation time, particle size was $75 \mathrm{~nm}$ with a yield of $54.4 \%$, and a growth period of 220 hours. Holmberg et al. added $\mathrm{TMABr}$ in clear solution to control the particle size of nanoFAU zeolite and reported nanoFAU of $37 \mathrm{~nm}$ with an yield of $12.5 \%$ over a period of 96 hours [24,38]. Their synthesis composition has been employed in this study. Using organic solvent to protect colloidal nanoFAU zeolite from aggregation has also been reported [39]. With this method, zeolite particle size was decreased from $400 \mathrm{~nm}$ to $27 \mathrm{~nm}$ and synthesis took 72 hours, but the yield was not specified. NanoFAU with diameter between $20-30 \mathrm{~nm}$ and in 140 hours has been reported, but the yield was not specified [40]. Song et al. successfully increased yield of $30 \mathrm{~nm}$ nanoFAU to $43 \%$ by reusing the supernatant 10 times, over a course of 576 hours, with $\mathrm{Si} / \mathrm{Al}$ ratios of the nanoFAU around 1.8 [20]. In most of these studies, where the yields are reported, the synthesis rates are typically around $0.1 \%$ per hour, even with mid-synthesis $\mathrm{Na}^{+}$addition. Compared with literature, 
yield (93\%) and time of synthesis (29 hours) for nanoFAU of size $29 \mathrm{~nm}$, and $\mathrm{Si} / \mathrm{Al}$ of 1.73 is significantly improved with the present DRHT method.

\subsection{Practical Implications}

There are three issues with the nanozeolites synthesized by the rapid DRHT method that are relevant to their practical applications. First is cost. This is difficult to estimate since the eventual price point is determined by demand. However, if we compare the previous best method [20] to the DRHT method, the principal savings of the latter are in electricity costs (29 hours of heating as compared to 24 days of heating), and also twice the yield. Prices for commercial sources of micron-sized zeolites are available, but since we carried out our experiment on the laboratory scale, price with scaling to industrial scale is difficult to estimate. One comparison is to compare the costs of materials for nanozeolites and micron-sized zeolites, both from laboratory scale suppliers. We have provided this information in Table 1S. A typical synthesis as described in the Experimental Section has materials cost of $\$ 6.06$ for $10.2 \mathrm{~g}$ of nanoFAU. Using costs of chemicals for micron-sized zeolite $\mathrm{X}$ and $\mathrm{Y}$ from a well-vetted published source [41], we estimate $\$ 28.22$ for $42 \mathrm{~g}$ of zeolite $\mathrm{X}$ and $\$ 1.43$ for $32 \mathrm{~g}$ of zeolite $\mathrm{Y}$. These calculations provide some perspective on the projected costs of nanozeolite versus micron-sized zeolites.

Second issue is the use of TMA compounds in the manufacture of nanoFAU. TMAOH is a toxic material and can cause severe burns [42]. However, TMAOH is used extensively in the semiconductor industry, and so appropriate handling of this material is well established.

Third issue is the presence of TMA cations in the supercage and the sodalite cage of the synthesized zeolite. Raman spectroscopy is a convenient way to identify the presence of $\mathrm{TMA}^{+}$ since the C-N vibration of the $\mathrm{TMA}^{+}$in the supercage $\left(752 \mathrm{~cm}^{-1}\right)$ is distinct from that in the sodalite cage $\left(767 \mathrm{~cm}^{-1}\right)$ [43]. Figure 11S shows the Raman spectrum of nanoFAU, and both 
these bands are observed. The elemental analysis of the nanoFAU before (C-4.62\%. N-1.29\%), and after $(\mathrm{C}-2.69 \%, \mathrm{~N}-0.72 \%) \mathrm{Na}^{+}$ion-exchange indicates about $0.75 \mathrm{TMA}^{+} /$supercage, and $0.44 \mathrm{TMA}^{+} /$sodalite cage (complete dehydration of the zeolite is assumed, though sample was dried at $100{ }^{\circ} \mathrm{C}$ for 24 hours). The $\mathrm{TMA}^{+}$in the supercage can be removed by ion-exchange, and is confirmed in Figure 11S. To remove the $\mathrm{TMA}^{+}$from the sodalite cage, samples need to be calcined. Upon calcination, there is significant aggregation, as shown by the TEM and DLS in Figure 12S. The size increases to greater than a micron (by DLS) upon calcination; with sonication in an ultrasonic bath for 4 hours, the size decreases to about $200 \mathrm{~nm}$ (DLS).

\section{Conclusion}

In this study, synthesis parameters were optimized for a previously reported composition $0.048 \mathrm{Na}_{2} \mathrm{O}: 2.40$ (TMA) $)_{2} \mathrm{O}(2 \mathrm{OH}): 1.2(\mathrm{TMA})_{2} \mathrm{O}(2 \mathrm{Br}): 4.35 \mathrm{SiO}_{2}: 1.0 \mathrm{Al}_{2} \mathrm{O}_{3}: 249 \mathrm{H}_{2} \mathrm{O}(\mathrm{Comp} \mathrm{A})$ to maximize the synthesis rate and yield of nanoFAU. Both microwave and dehydration rehydration hydrothermal (DRHT) speeded up nanoFAU formation from a 3-day aged Comp A (AgCompA), though the former led to large crystals of zeolite A. The supernatant recovered from the hydrothermal or DRHT process for AgCompA was used for further rapid synthesis of nanoFAU by repeated cycling with DRHT process with mid-synthesis $\mathrm{NaOH}$ addition during the rehydration step. The optimum DRHT procedure provides a yield of 93\% nanoFAU with 29 hours of synthesis time, and nanoFAU of size $29 \mathrm{~nm}, \mathrm{Si} / \mathrm{Al}$ of 1.73 , and surface area of $625 \mathrm{~m}^{2} / \mathrm{g}$. Overall synthesis rate with DRHT is improved to $3 \%$ per hour, as compared to $0.1 \%$ for the regular hydrothermal process.

\section{AUTHOR INFORMATION}

Corresponding Author 
*Prabir K. Dutta, dutta@chemistry.ohio-state.edu

\section{Author Contributions}

This manuscript is based on the $\mathrm{PhD}$ thesis of Bo Wang, who did the bulk of the work. The paper was written through contributions of all authors. All authors have given approval to the final version of the manuscript.

\section{Funding Sources}

This work is funded by The U. S. Department of Energy under Award Number DE-FE0007632. However, any opinions, findings, conclusions, or recommendations expressed herein are those of the author(s) and do not necessarily reflect the views of the DOE.

\section{ACKNOWLEDGMENT}

Authors would like to thank Hendrik Colijn for his help collecting TEM images. 


\section{Reference}

[1] S.M. Auerbach, K.A. Carrado, P.K. Dutta, Handbook of Zeolite Science and Technology, CRC Press, 2003.

[2] D. Verboekend, N. Nuttens, R. Locus, J.V. Aelst, P. Verolme, J.C. Groen, et al., Synthesis, characterization, and catalytic evaluation of hierarchical faujasite zeolites: milestones, challenges, and future directions, Chem. Soc. Rev. (2015). doi:10.1039/C5CS00520E.

[3] V. Valtchev, L. Tosheva, Porous Nanosized Particles: Preparation, Properties, and Applications, Chem. Rev. 113 (2013) 6734-6760. doi:10.1021/cr300439k.

[4] T. Ennaert, J.V. Aelst, J. Dijkmans, R.D. Clercq, W. Schutyser, M. Dusselier, et al., Potential and challenges of zeolite chemistry in the catalytic conversion of biomass, Chem. Soc. Rev. 45 (2016) 584-611. doi:10.1039/C5CS00859J.

[5] J. Gascon, F. Kapteijn, B. Zornoza, V. Sebastián, C. Casado, J. Coronas, Practical Approach to Zeolitic Membranes and Coatings: State of the Art, Opportunities, Barriers, and Future Perspectives, Chem. Mater. 24 (2012) 2829-2844. doi:10.1021/cm301435j.

[6] Y. Zheng, X. Li, P.K. Dutta, Exploitation of Unique Properties of Zeolites in the Development of Gas Sensors, Sensors. 12 (2012) 5170-5194. doi:10.3390/s120405170.

[7] S. Mintova, J.-P. Gilson, V. Valtchev, Advances in nanosized zeolites, Nanoscale. 5 (2013) 6693-6703. doi:10.1039/C3NR01629C.

[8] J. Del-Pilar, B. Wang, P.K. Dutta, Anchoring of cobalt hydroxide catalysts on nanozeolite crystals for photocatalytic water oxidation, Microporous Mesoporous Mater. 217 (2015) 125-132. doi:10.1016/j.micromeso.2015.06.014. 
[9] C. Platas-Iglesias, L. Vander Elst, W. Zhou, R.N. Muller, C.F.G.C. Geraldes, T. Maschmeyer, et al., Zeolite GdNaY Nanoparticles with Very High Relaxivity for Application as Contrast Agents in Magnetic Resonance Imaging, Chem. - Eur. J. 8 (2002) 5121-5131. doi:10.1002/1521-3765(20021115)8:22<5121::AID-CHEM5121>3.0.CO;2-W.

[10] L. Tosheva, V.P. Valtchev, Nanozeolites: Synthesis, Crystallization Mechanism, and Applications, Chem. Mater. 17 (2005) 2494-2513. doi:10.1021/cm047908z.

[11] B.J. Schoeman, J. Sterte, J.-E. Otterstedt, Colloidal zeolite suspensions, Zeolites. 14 (1994) 110-116. doi:10.1016/0144-2449(94)90004-3.

[12] M. Severance, B. Wang, K. Ramasubramanian, L. Zhao, W.S.W. Ho, P.K. Dutta, Rapid Crystallization of Faujasitic Zeolites: Mechanism and Application to Zeolite Membrane Growth on Polymer Supports, Langmuir. 30 (2014) 6929-6937. doi:10.1021/la5004512.

[13] B. Wang, W.S.W. Ho, J.D. Figueroa, P.K. Dutta, Bendable Zeolite Membranes: Synthesis and Improved Gas Separation Performance, Langmuir. 31 (2015) 6894-6901. doi:10.1021/acs.langmuir.5b01306.

[14] B. Wang, C. Sun, Y. Li, L. Zhao, W.S.W. Ho, P.K. Dutta, Rapid synthesis of faujasite/polyethersulfone composite membrane and application for $\mathrm{CO} 2 / \mathrm{N} 2$ separation, Microporous Mesoporous Mater. 208 (2015) 72-82. doi:10.1016/j.micromeso.2015.01.020.

[15] Y. Chen, B. Wang, L. Zhao, P. Dutta, W.S. Winston Ho, New Pebax®/zeolite Y composite membranes for CO2 capture from flue gas, J. Membr. Sci. 495 (2015) 415-423. doi:10.1016/j.memsci.2015.08.045.

[16] Y. Chen, L. Zhao, B. Wang, P. Dutta, W.S. Winston Ho, Amine-containing polymer/zeolite Y composite membranes for CO2/N2 separation, J. Membr. Sci. 497 (2016) 21-28. doi:10.1016/j.memsci.2015.09.036. 
[17] B. Wang, E.A. Jackson, J.W. Hoff, P.K. Dutta, Fabrication of zeolite/polymer composite membranes in a roller assembly, Microporous Mesoporous Mater. 223 (2016) 247-253. doi:10.1016/j.micromeso.2015.11.003.

[18] L. Zhao, Y. Chen, B. Wang, C. Sun, S. Chakraborty, K. Ramasubramanian, et al., Multilayer polymer/zeolite $\mathrm{Y}$ composite membrane structure for $\mathrm{CO} 2$ capture from flue gas, J. Membr. Sci. 498 (2016) 1-13. doi:10.1016/j.memsci.2015.10.006.

[19] T.C. Merkel, H. Lin, X. Wei, R. Baker, Power plant post-combustion carbon dioxide capture: An opportunity for membranes, J. Membr. Sci. 359 (2010) 126-139. doi:10.1016/j.memsci.2009.10.041.

[20] W. Song, V.H. Grassian, S.C. Larsen, High yield method for nanocrystalline zeolite synthesis, Chem. Commun. (2005) 2951-2953. doi:10.1039/B501768H.

[21] G. Zhu, S. Qiu, J. Yu, Y. Sakamoto, F. Xiao, R. Xu, et al., Synthesis and Characterization of High-Quality Zeolite LTA and FAU Single Nanocrystals, Chem. Mater. 10 (1998) 14831486. doi:10.1021/cm980061k.

[22] S. Mintova, N.H. Olson, T. Bein, Electron Microscopy Reveals the Nucleation Mechanism of Zeolite Y from Precursor Colloids, Angew. Chem. Int. Ed. 38 (1999) 32013204. doi:10.1002/(SICI)1521-3773(19991102)38:21<3201::AID-ANIE3201>3.0.CO;2-H.

[23] Q. Li, D. Creaser, J. Sterte, An Investigation of the Nucleation/Crystallization Kinetics of Nanosized Colloidal Faujasite Zeolites, Chem. Mater. 14 (2002) 1319-1324. doi:10.1021/cm011242g.

[24] B.A. Holmberg, H. Wang, J.M. Norbeck, Y. Yan, Controlling size and yield of zeolite Y nanocrystals using tetramethylammonium bromide, Microporous Mesoporous Mater. 59 (2003) 13-28. doi:10.1016/S1387-1811(03)00271-3. 
[25] S. Mintova, V. Valtchev, Synthesis of nanosized FAU-type zeolite, in: G.P.-B. I. Kiricsi J.B. Nagy and H.G. Karge (Ed.), Stud. Surf. Sci. Catal., Elsevier, 1999: pp. 141-148. http://www.sciencedirect.com/science/article/pii/S0167299199802079 (accessed July 23, 2014).

[26] H. Awala, J.-P. Gilson, R. Retoux, P. Boullay, J.-M. Goupil, V. Valtchev, et al., Template-free nanosized faujasite-type zeolites, Nat. Mater. 14 (2015) 447-451. doi:10.1038/nmat4173.

[27] C.S. Cundy, J.P. Zhao, Remarkable synergy between microwave heating and the addition of seed crystals in zeolite synthesis — a suggestion verified, Chem. Commun. (1998) 14651466. doi:10.1039/A803324B.

[28] Z. Liu, T. Wakihara, D. Nishioka, K. Oshima, T. Takewaki, T. Okubo, Ultrafast Continuous-Flow Synthesis of Crystalline Microporous Aluminophosphate AlPO4-5, Chem. Mater. 26 (2014) 2327-2331. doi:10.1021/cm500287g.

[29] G.A. Tompsett, W.C. Conner, K.S. Yngvesson, Microwave Synthesis of Nanoporous Materials, ChemPhysChem. 7 (2006) 296-319. doi:10.1002/cphc.200500449.

[30] H. Katsuki, S. Furuta, S. Komarneni, Microwave Versus Conventional-Hydrothermal Synthesis of NaY Zeolite, J. Porous Mater. 8 (2001) 5-12. doi:10.1023/A:1026583832734.

[31] Z. Cheng, S. Han, W. Sun, Q. Qin, Microwave-assisted synthesis of nanosized FAU-type zeolite in water-in-oil microemulsion, Mater. Lett. 95 (2013) 193-196. doi:10.1016/j.matlet.2013.01.002.

[32] M. Ansari, A. Aroujalian, A. Raisi, B. Dabir, M. Fathizadeh, Preparation and characterization of nano-NaX zeolite by microwave assisted hydrothermal method, Adv. Powder Technol. 25 (2014) 722-727. doi:10.1016/j.apt.2013.10.021. 
[33] J. Lim, S.P. Yeap, H.X. Che, S.C. Low, Characterization of magnetic nanoparticle by dynamic light scattering, Nanoscale Res. Lett. 8 (2013) 381. doi:10.1186/1556-276X-8-381.

[34] G. Majano, A. Darwiche, S. Mintova, V. Valtchev, Seed-Induced Crystallization of Nanosized Na-ZSM-5 Crystals, Ind. Eng. Chem. Res. 48 (2009) 7084-7091. doi:10.1021/ie8017252.

[35] Y.C. Kim, J.Y. Jeong, J.Y. Hwang, S.D. Kim, W.J. Kim, Influencing factors on rapid crystallization of high silica nano-sized zeolite $\mathrm{Y}$ without organic template under atmospheric pressure, J. Porous Mater. 16 (2008) 299-306. doi:10.1007/s10934-008-9200-4.

[36] S. Inagaki, K. Thomas, V. Ruaux, G. Clet, T. Wakihara, S. Shinoda, et al., Crystal Growth Kinetics as a Tool for Controlling the Catalytic Performance of a FAU-Type Basic Catalyst, ACS Catal. 4 (2014) 2333-2341. doi:10.1021/cs500153e.

[37] H. Lechert, H. Kacirek, The kinetics of nucleation of X zeolites, Zeolites. 13 (1993) 192200. doi:10.1016/S0144-2449(05)80277-5.

[38] B.A. Holmberg, H. Wang, Y. Yan, High silica zeolite Y nanocrystals by dealumination and direct synthesis, Microporous Mesoporous Mater. 74 (2004) 189-198. doi:10.1016/j.micromeso.2004.06.018.

[39] G.-T. Vuong, T.-O. Do, A New Route for the Synthesis of Uniform Nanozeolites with Hydrophobic External Surface in Organic Solvent Medium, J. Am. Chem. Soc. 129 (2007) 3810-3811. doi:10.1021/ja069058p.

[40] P. Morales-Pacheco, F. Alvarez, L. Bucio, J.M. Domínguez, Synthesis and Structural Properties of Zeolitic Nanocrystals II: FAU-Type Zeolites, J. Phys. Chem. C. 113 (2009) 2247-2255. doi:10.1021/jp8070713. 
[41] H. Robson, Verified Synthesis of Zeolitic Materials: Second Edition, 1 edition, Elsevier Science, Amsterdam; New York, 2001.

[42] C. -L. Wu, S. -B. Su, H. -Y. Lien, H. -R. Guo, The role of the chemical burns caused by hydroxide ion in the toxicity of dermal exposure to tetramethylammonium ion in a rat model, Burns 38 (2012) 1051-1057. doi:10.1016/j.burns.2012.02.027.

[43] P.K. Dutta, B. del Barco, D.C. Shieh, Raman spectroscopic studies of the tetramethylammonium ion in zeolite cages, Chem. Phys. Lett. 127 (1986) 200-204. doi:10.1016/S0009-2614(86)80279-2. 
Table 1. Characteristics of nanoFAU prepared in this study

\begin{tabular}{|c|c|c|c|c|c|c|c|}
\hline Reactant & $\begin{array}{l}\text { Synthesis } \\
\text { Methods }\end{array}$ & $\begin{array}{c}\text { Synthesis } \\
\text { Time/h }\end{array}$ & Product & $\begin{array}{c}\text { Size of } \\
\text { FAU/nm } \\
\text { (DLS) }\end{array}$ & $\begin{array}{c}\text { Size of } \\
\text { FAU/nm } \\
(\text { TEM) }\end{array}$ & $\mathrm{Si} / \mathrm{Al}$ & $\begin{array}{l}\text { FAU } \\
\text { Yield } \\
/ \%\end{array}$ \\
\hline \multirow{4}{*}{ AgComp A } & $\begin{array}{l}\text { Hydrothermal } \\
\text { (HT) }\end{array}$ & 96 & FAU & 40 & - & 2.11 & 5 \\
\hline & Seeding/HT & 96 & FAU & 56 & - & - & 6 \\
\hline & Microwave & 4 & $\begin{array}{c}\text { FAU+ } \\
\text { LTA }\end{array}$ & 96 & - & - & 7 \\
\hline & DRHT-20h $^{\#}$ & 20 & FAU & 64 & $21 \pm 4$ & 2.23 & 10 \\
\hline \multirow{3}{*}{$\begin{array}{l}\text { SupHTAg } \\
\text { Comp A* }\end{array}$} & $\begin{array}{l}\text { Microwave- } \\
3 \text { cycles }\end{array}$ & 3 & FAU & 45 & - & - & 35 \\
\hline & $\begin{array}{c}\text { 2-cycle } \\
\text { DRHT-4h! }\end{array}$ & 4 & FAU & 54 & - & - & 62 \\
\hline & $\begin{array}{c}\text { 6-cycle } \\
\text { DRHT-9h }^{+}\end{array}$ & 9 & FAU & 60 & $31 \pm 4$ & 1.52 & 76 \\
\hline AgComp A & $\begin{array}{c}\text { DRHT- } \\
\text { Continuous" }\end{array}$ & 29 & FAU & 89 & $29 \pm 7$ & 1.76 & 93 \\
\hline
\end{tabular}

* Supernatant after initial HT crystal growth of AgComp A (96 hours)

\# DRHT process: 30 min of dehydration +19 hours of reflux +30 min of rehydration

'Each cycle of DRHT process: 30 min of dehydration +1 hour of reflux +30 min of rehydration with aq $\mathrm{NaOH}$

${ }^{+}$Each cycle of DRHT process: 30 min of dehydration +30 min of reflux +30 min of rehydration with aq $\mathrm{NaOH}$

"DRHT Continuous: Initial DRHT: 30 min of dehydration +19 hour of reflux +30 min of rehydration followed by 6 cycles of : 30 min of dehydration +1 hour of reflux +30 min of rehydration with aq $\mathrm{NaOH}$ 
Table 2. Reported nanoFAU clear-solution synthesis methods

\begin{tabular}{|c|c|c|c|c|c|c|c|}
\hline Composition & $\begin{array}{l}\text { Aging } \\
\text { Time }\end{array}$ & Heating & $\begin{array}{l}\text { Heating } \\
\text { Method }\end{array}$ & $\mathrm{Si} / \mathrm{Al}$ & $\begin{array}{l}\text { Size } \\
/ \mathrm{nm}\end{array}$ & $\begin{array}{c}\text { Yield } \\
1 \%\end{array}$ & Ref \\
\hline $\begin{array}{l}0.04 \mathrm{Na}_{2} \mathrm{O}: 2.46(\mathrm{TMA})_{2} \mathrm{O}: \\
3.4 \mathrm{SiO}_{2}: \mathrm{Al}_{2} \mathrm{O}_{3}: 370 \mathrm{H}_{2} \mathrm{O}\end{array}$ & NR & $\begin{array}{c}100^{\circ} \mathrm{C}, \\
100 \mathrm{~h}\end{array}$ & Hydrothermal & NR & 100 & NR & [11] \\
\hline $\begin{array}{c}\left.\text { 0.065 } \mathrm{Na}_{2} \mathrm{O}: 2.39 \text { (TMA) }\right)_{2} \mathrm{O}: \\
\text { 4.3 } \mathrm{SiO}_{2}: \mathrm{Al}_{2} \mathrm{O}_{3}: 248 \mathrm{H}_{2} \mathrm{O}\end{array}$ & $\begin{array}{c}30 \\
\min \end{array}$ & $\begin{array}{l}100^{\circ} \mathrm{C}, \\
50 \mathrm{~h}\end{array}$ & Hydrothermal & 2.15 & 50 & NR & {$[22,25]$} \\
\hline $\begin{array}{c}0.048 \mathrm{Na}_{2} \mathrm{O}: 2.40 \\
(\mathrm{TMA})_{2} \mathrm{O}(2 \mathrm{OH}): 1.2 \\
(\mathrm{TMA})_{2} \mathrm{O}(2 \mathrm{Br}): 4.35 \mathrm{SiO}_{2} \text { : } \\
\mathrm{Al}_{2} \mathrm{O}_{3}: 249 \mathrm{H}_{2} \mathrm{O}\end{array}$ & $\begin{array}{c}4 \\
\text { days }\end{array}$ & $\begin{array}{l}100^{\circ} \mathrm{C}, \\
96 \mathrm{~h}\end{array}$ & Hydrothermal & 2.38 & 37 & 12.5 & {$[24,38]$} \\
\hline $\begin{array}{c}0.07 \mathrm{Na}_{2} \mathrm{O}: 2.4(\mathrm{TMA})_{2} \mathrm{O}: \\
4 \mathrm{SiO}_{2}: \mathrm{Al}_{2} \mathrm{O}_{3}: 264 \mathrm{H}_{2} \mathrm{O}\end{array}$ & $\begin{array}{c}24 \\
\text { hours }\end{array}$ & $\begin{array}{c}150^{\circ} \mathrm{C}, \\
72 \mathrm{~h}\end{array}$ & $\begin{array}{c}\text { Organic } \\
\text { Hydrothermal }\end{array}$ & NR & 27 & NR & [39] \\
\hline $\begin{array}{c}0.032 \mathrm{Na}_{2} \mathrm{O}: 2.46(\mathrm{TMA})_{2} \mathrm{O}: \\
\text { 3.40 } \mathrm{SiO}_{2}: \mathrm{Al}_{2} \mathrm{O}_{3}: 370 \mathrm{H}_{2} \mathrm{O}: \\
\text { 13.6 EtOH }\end{array}$ & $\begin{array}{c}24 \\
\text { hours }\end{array}$ & $\begin{array}{l}100{ }^{\circ} \mathrm{C}, \\
220 \mathrm{~h}\end{array}$ & Hydrothermal & 1.89 & 75 & 54.4 & {$[23]$} \\
\hline $\begin{array}{l}\text { 0.12 NaCl: } 2.8 \text { (TMA) })_{2} \mathrm{O} \\
16.1 \mathrm{SiO}_{2}: \mathrm{Al}_{2} \mathrm{O}_{3}: 361 \mathrm{H}_{2} \mathrm{O}\end{array}$ & $\begin{array}{c}2 \\
\text { days }\end{array}$ & $\begin{array}{c}100^{\circ} \mathrm{C}, \\
336 \mathrm{~h}\end{array}$ & Hydrothermal & 1.80 & 80 & NR & {$[21]$} \\
\hline $\begin{array}{c}\left.0.032 \mathrm{Na}_{2} \mathrm{O}: 2.4 \text { (TMA) }\right)_{2} \mathrm{O}: \\
\text { 3.4 } \mathrm{SiO}_{2}: \mathrm{Al}_{2} \mathrm{O}_{3}: 370 \mathrm{H}_{2} \mathrm{O}\end{array}$ & $\begin{array}{c}24 \\
\text { hours }\end{array}$ & $\begin{array}{l}95^{\circ} \mathrm{C}, \\
140 \mathrm{~h}\end{array}$ & Hydrothermal & 1.70 & 22 & NR & {$[40]$} \\
\hline $\begin{array}{c}0.07 \mathrm{Na}_{2} \mathrm{O}: 2.4(\mathrm{TMA})_{2} \mathrm{O}: \\
\text { 4.0 } \mathrm{SiO}_{2}: \mathrm{Al}_{2} \mathrm{O}_{3}: 266 \mathrm{H}_{2} \mathrm{O}: \\
\text { 6.0 i-PrOH: } 16.0 \mathrm{EtOH}\end{array}$ & NR & $\begin{array}{l}90^{\circ} \mathrm{C}, \\
576 \mathrm{~h}\end{array}$ & $\begin{array}{c}\text { Repeating } \\
\text { Hydrothermal }\end{array}$ & 1.83 & 30 & 43 & {$[20]$} \\
\hline $\begin{array}{c}9 \mathrm{Na}_{2} \mathrm{O}: 0.7 \mathrm{Al}_{2} \mathrm{O}_{3}: 10 \mathrm{SiO}_{2}: \\
160 \mathrm{H}_{2} \mathrm{O}\end{array}$ & $\begin{array}{c}24 \\
\text { hours }\end{array}$ & $\begin{array}{l}50^{\circ} \mathrm{C} \\
45 \mathrm{~h}\end{array}$ & Hydrothermal & 1.60 & 10 & 80 & {$[26]$} \\
\hline $\begin{array}{c}0.048 \mathrm{Na}_{2} \mathrm{O}: 2.40 \\
(\mathrm{TMA})_{2} \mathrm{O}(2 \mathrm{OH}): 1.2 \\
(\mathrm{TMA})_{2} \mathrm{O}(2 \mathrm{Br}): 4.35 \mathrm{SiO}_{2} \text { : } \\
\mathrm{Al}_{2} \mathrm{O}_{3}: 249 \mathrm{H}_{2} \mathrm{O}\end{array}$ & $\begin{array}{c}3 \\
\text { days }\end{array}$ & $\begin{array}{l}100^{\circ} \mathrm{C}, \\
29 \mathrm{~h}\end{array}$ & $\begin{array}{l}\text { Hydrothermal } \\
\text { + Rapid } \\
\text { Method }\end{array}$ & 1.76 & 30 & 93 & This \\
\hline
\end{tabular}




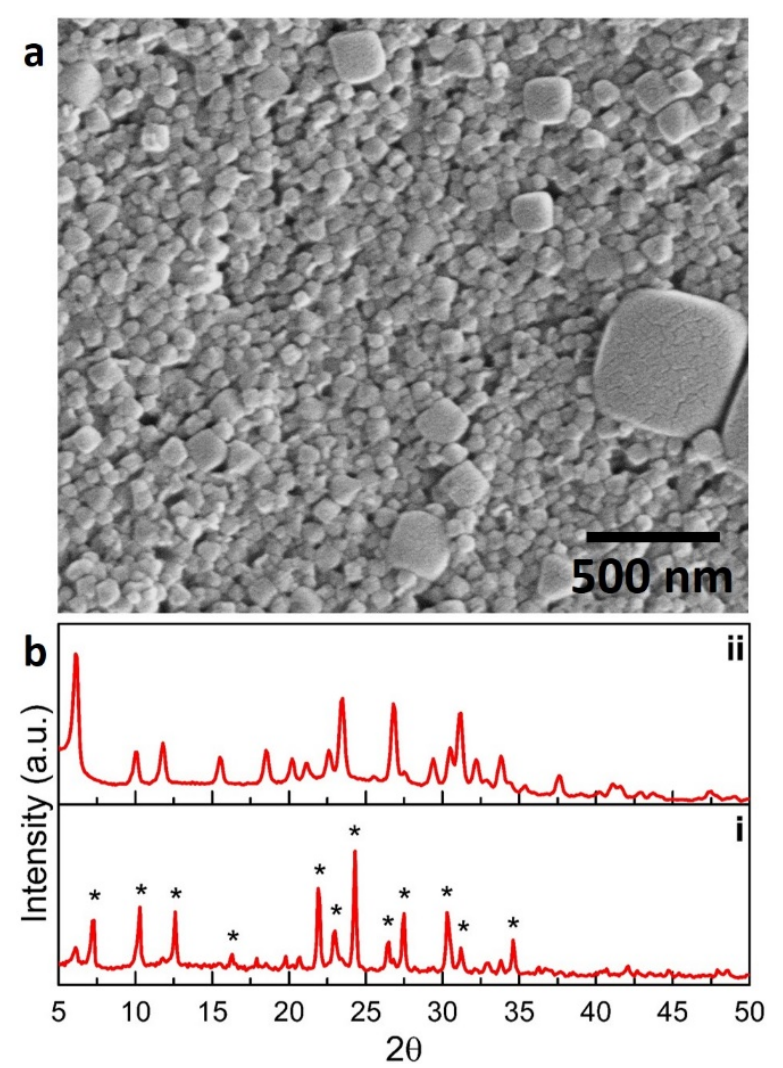

Figure 1. (a). SEM image of product isolated from MW treated AgComp A; (b). XRD patterns of (i) large and (ii) small particles obtained from MW synthesis of AgComp A (4 hours, * marks zeolite A patterns) 

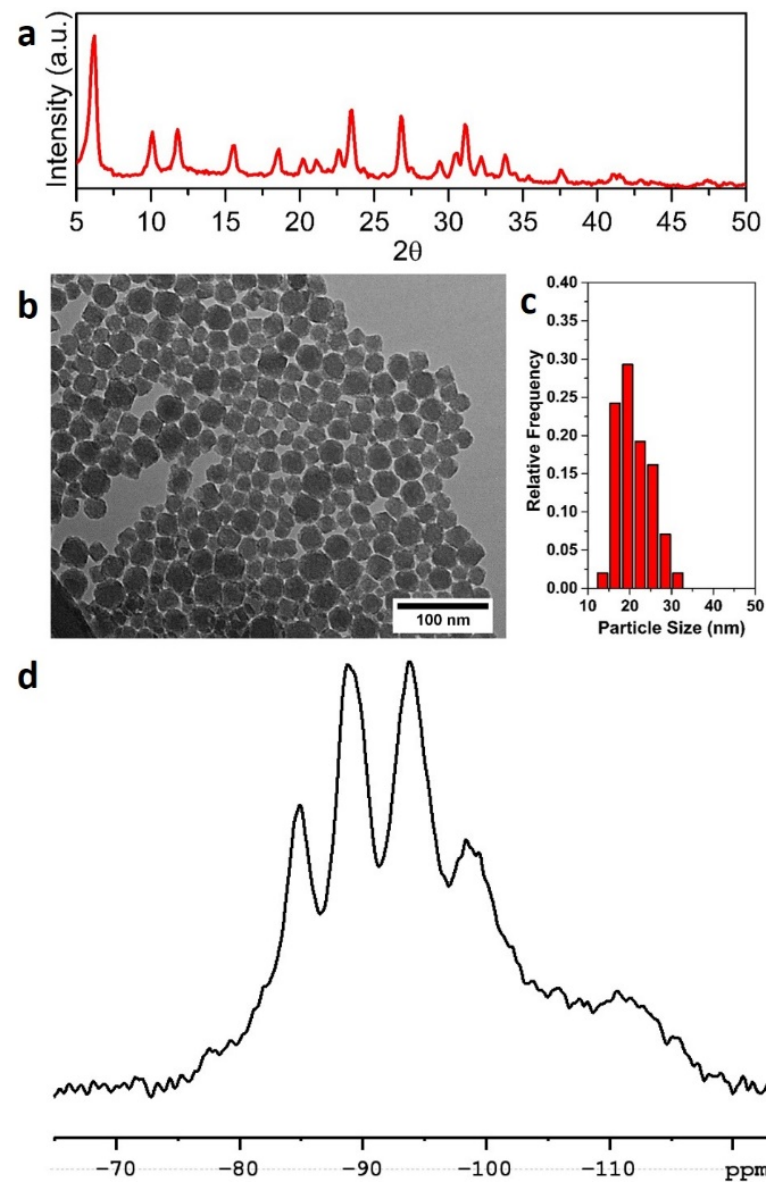

Figure 2. (a). XRD pattern, (b). TEM image, (c). particle size distribution and (d). ${ }^{29} \mathrm{Si}$ Solid State NMR spectrum of nanoFAU particles isolated from 20 hours DRHT process from AgComp A. (DRHT process involved: 30 min of dehydration +19 hours of reflux +30 min of rehydration) 

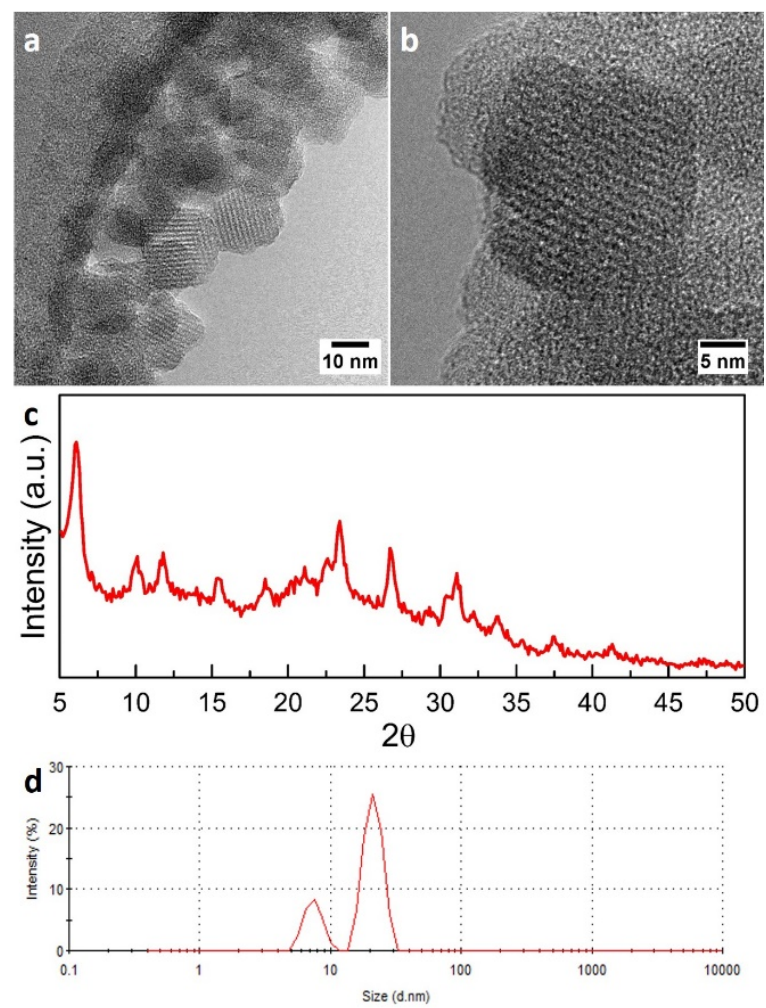

Figure 3. (a) Low and (b) high resolution TEM images, (c) XRD pattern and (d) DLS size distribution of particles isolated from supernatant of AgComp A after a 96 hour hydrothermal process. 

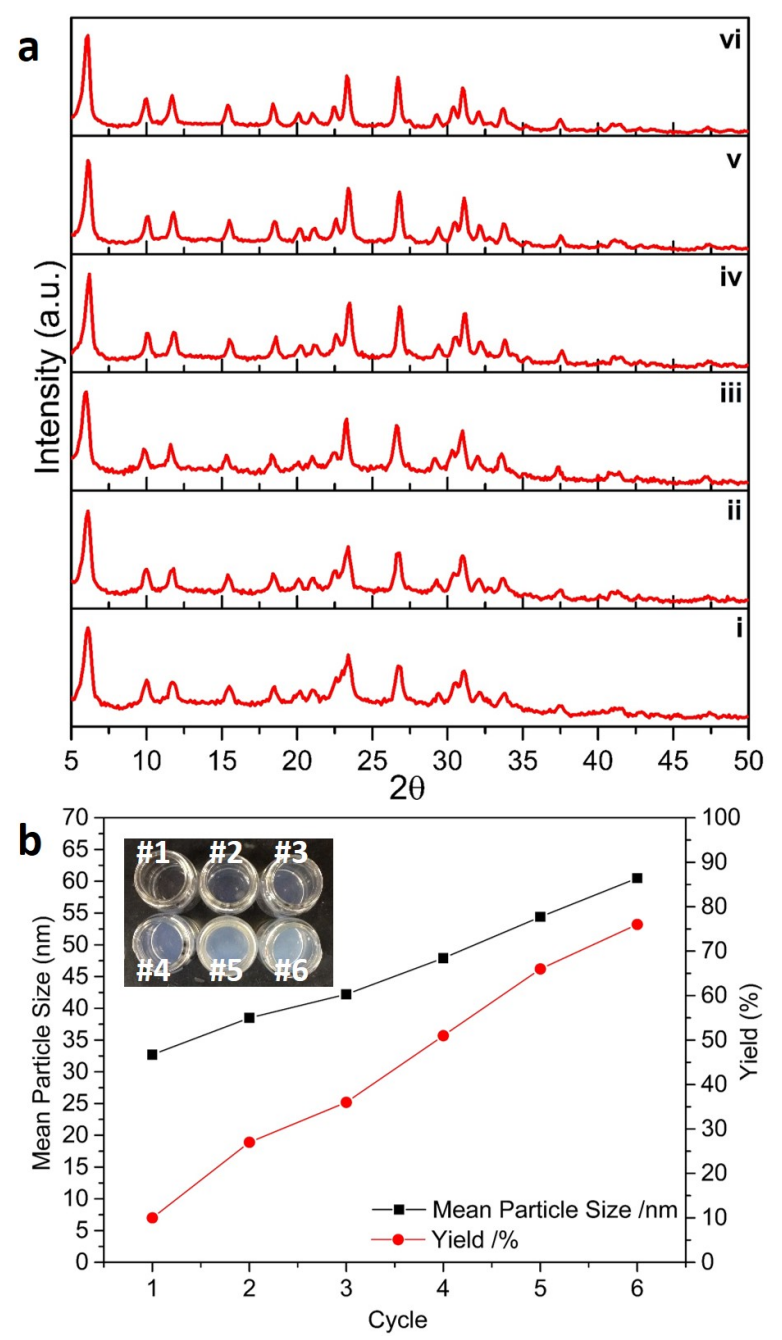

Figure 4. (a). XRD patterns and (b). particle size (DLS) and yield change of nanoFAU formed by the DRHT process after the (i). $1^{\text {st }}$, (ii). $2^{\text {nd }}$, (iii). $3^{\text {rd }}$, (iv). $4^{\text {th }},(\mathrm{v}) \cdot 5^{\text {th }}$ and (vi). $6^{\text {th }}$ heating cycle of supernatant recovered from AgCompA after conventional hydrothermal treatment (96 hours). Each cycle of the DRHT process is: $30 \mathrm{~min}$ of dehydration $+30 \mathrm{~min}$ of reflux $+30 \mathrm{~min}$ of rehydration with aq $\mathrm{NaOH}$. 


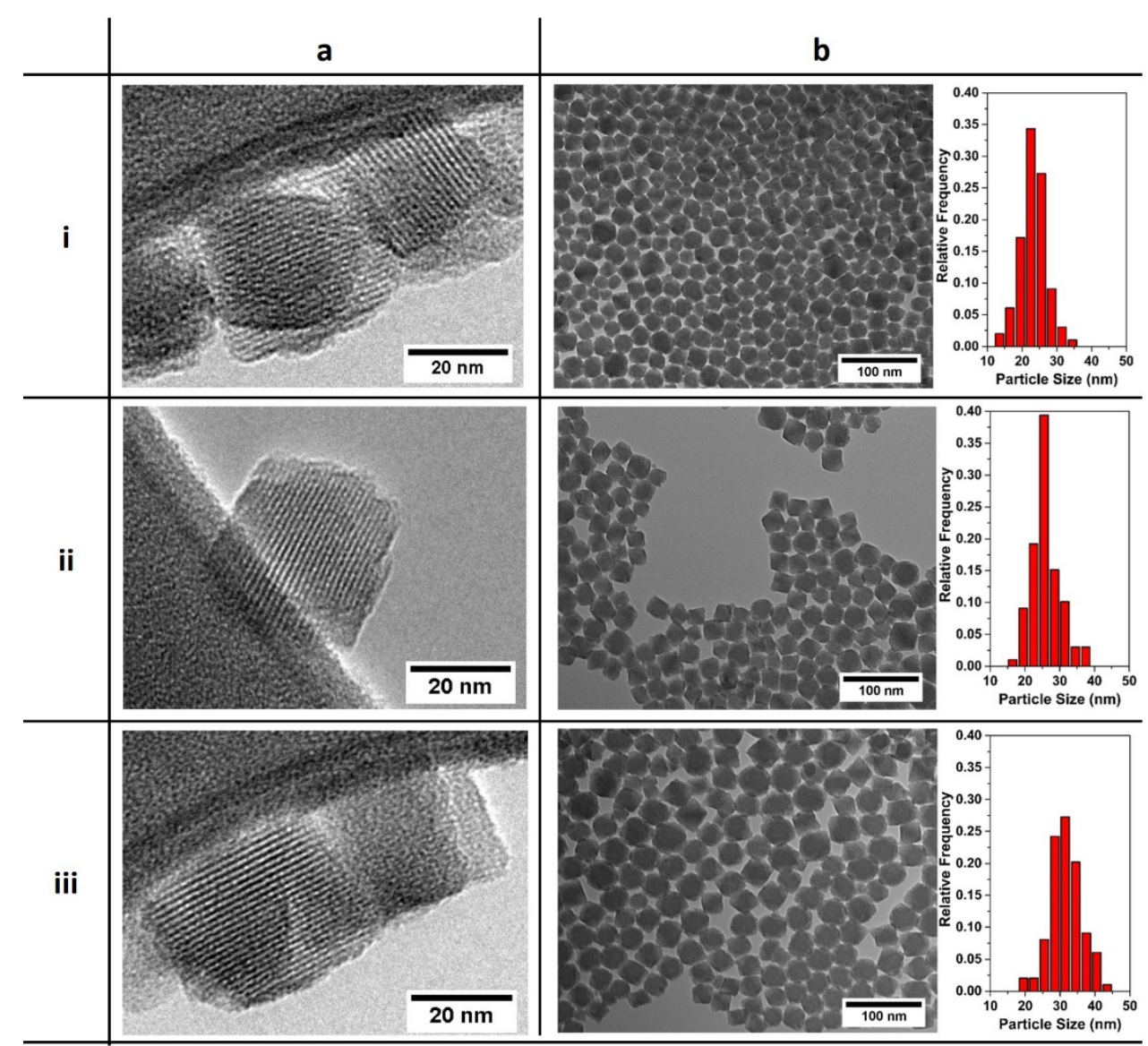

Figure 5. (a). High and (b). low magnification TEM images with particle size distributions of (i). DRHT-2 cycle, (ii). DRHT-4 cycle and (iii). DRHT-6 cycle particles. Each DRHT cycle includes 30 min of dehydration +30 min of reflux +30 min of rehydration with aq $\mathrm{NaOH}$ starting with the supernatant recovered from AgCompA after conventional hydrothermal treatment ( 96 hours). 


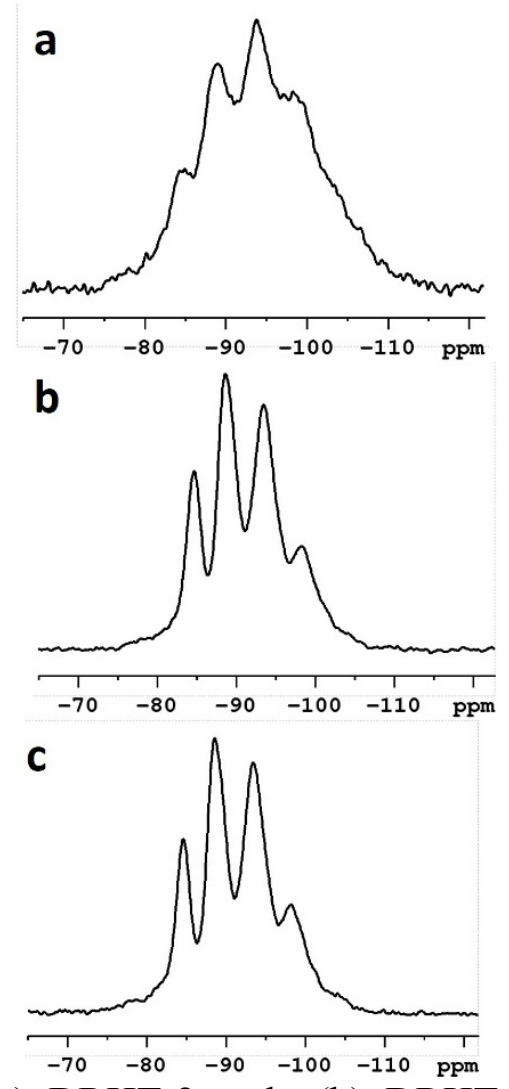

Figure 6. ${ }^{29} \mathrm{Si}$ NMR spectrum of (a). DRHT-2 cycle, (b). DRHT-4 cycle and (c). DRHT-6 cycle particles. Each DRHT cycle includes $30 \mathrm{~min}$ of dehydration $+30 \mathrm{~min}$ of reflux $+30 \mathrm{~min}$ of rehydration with aq $\mathrm{NaOH}$ using the supernatant recovered from AgCompA after conventional hydrothermal treatment (96 hours). 

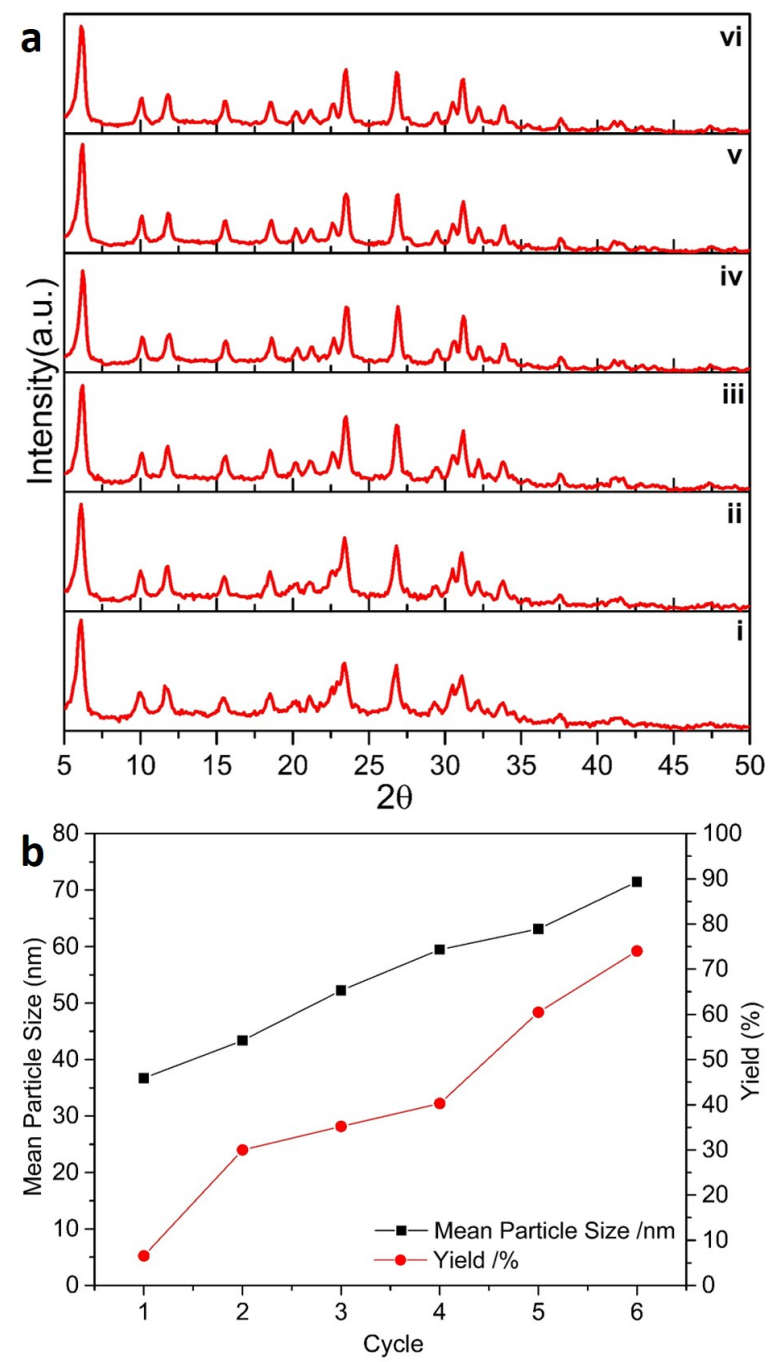

Figure 7. (a). XRD patterns and (b). particle size (DLS) and yield change of nanoFAU prepared by DRHT cycles $(30$ min of dehydration +30 min of reflux +30 min of rehydration with aq $\mathrm{NaOH})$ of the supernatant recovered from AgComp A which also went through the DRHT process ( $30 \mathrm{~min}$ of dehydration +19 hours of reflux $+30 \mathrm{~min}$ of rehydration) after the (i). $1^{\text {st }}$, (ii). $2^{\text {nd }}$, (iii). $3^{\text {rd }},\left(\right.$ iv) $.4^{\text {th }},(\mathrm{v}) .5^{\text {th }}$ and (vi). $6^{\text {th }}$ DRHT heating cycle. 

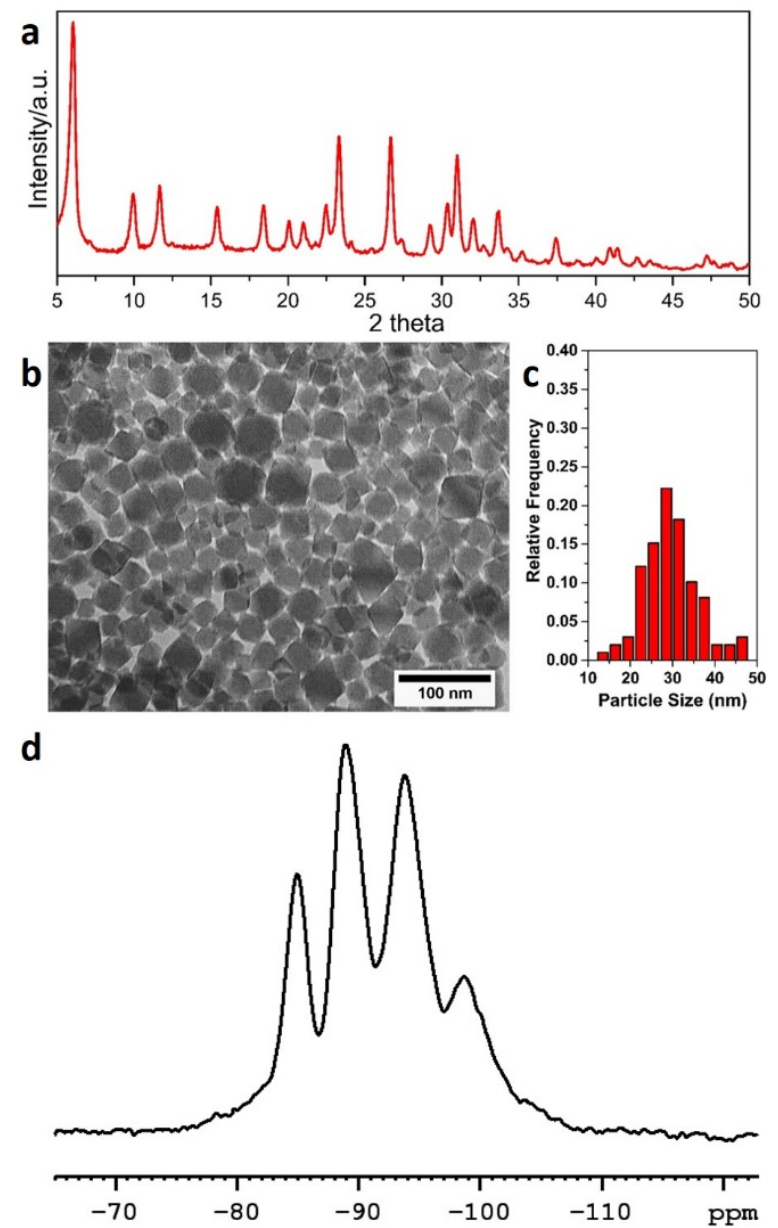

Figure 8. (a). XRD pattern, (b). TEM image, (c). particle size distribution and (d). ${ }^{29} \mathrm{Si}$ Solid State NMR spectrum of nanoFAU isolated from 29 hours continuous DRHT process on AgComp A. DRHT involved a first cycle of (30 min of dehydration +19 hours of reflux +30 min of rehydration) followed by 6 cycles of ( $30 \mathrm{~min}$ of dehydration $+30 \mathrm{~min}$ of reflux $+30 \mathrm{~min}$ of rehydration with aq $\mathrm{NaOH}$ ) without any intermediate separation steps. 

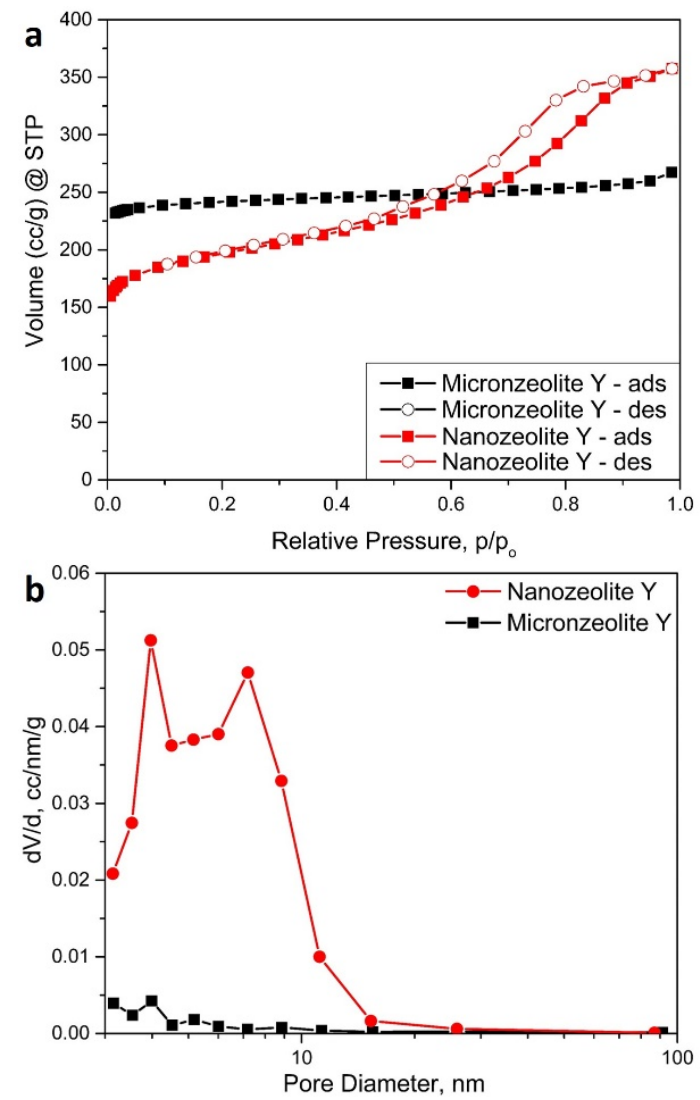

Figure 9. (a) $\mathrm{N}_{2}$ adsorption isotherm and (b) pore size distribution of close packed nanoFAU isolated from 29 hours continuous DRHT process, calculated with Barrett-Joyner-Halenda (BJH) method. DRHT involved a first cycle of (30 min of dehydration +19 hours of reflux +30 min of rehydration) followed by 6 cycles of ( $30 \mathrm{~min}$ of dehydration $+30 \mathrm{~min}$ of reflux $+30 \mathrm{~min}$ of rehydration with aq $\mathrm{NaOH}$ ) without any intermediate separation steps. 
Graphical abstract

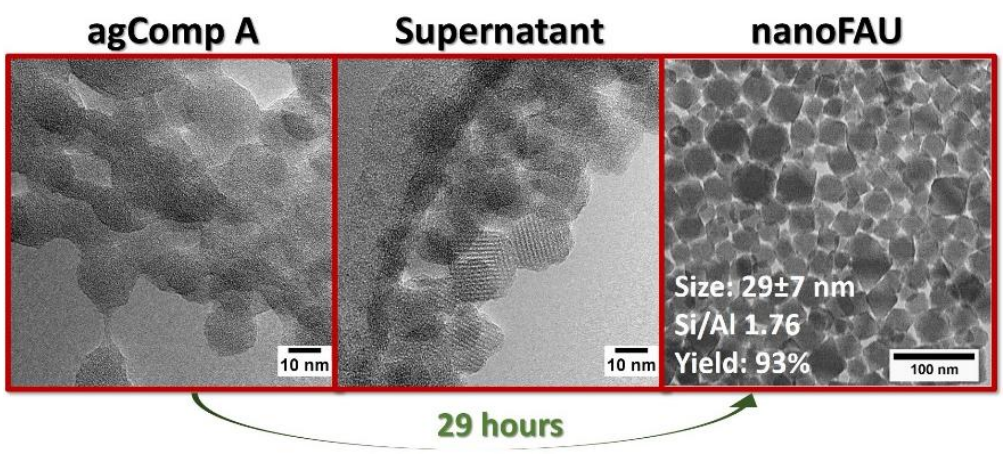

